\title{
Operationalizing Command Centre in COVID-19 Care Services in a Tertiary Care Teaching Hospital
}

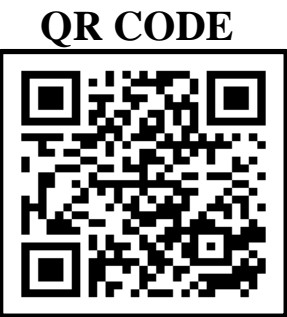

\section{SANIKA RATNAKAR KULKARNI'1, HENNA DHAR*}

COVID-19 was declared a public health emergency of international concern by WHO in March 2020. Hospitals were overburdened, health workers were drained and resources were depleting due to which people were desperately looking for hospital beds, medical oxygen and other necessities. For this purpose, a command centre was set up by the hospital administration department. The command centre targets for the enhancement of patient outcomes by coordination of care and centralized quality control. The main objectives of the command centre include internal communication between the departments concerned with COVID-19 care, appropriate resource allocation in the hospital for COVID-19 care and data compilation and dissemination of the real time data from COVID-19 war room to government organizations. The COVID-19 war room functions daily in a dedicated manner which helps in strategic planning and managing all the functions efficiently. The command centre though works dedicatedly, certain challenges are faced while carrying out the functions.

KEYWORDS: COVID-19, Strategic Planning, Hospital Administration, Tertiary Healthcare, Delivery of Healthcare

\section{INTRODUCTION}

COVID-19 was declared a public health emergency of international concern by WHO in March 2020. As of May 4, more than $20 \cdot 2$ million cases of COVID-19 had been reported, with an average of 378,00o cases a day, along with more than 222 ooo deaths, which experts were of the opinion that are likely to be substantial underestimates. ${ }^{1}$ Hospitals were overburdened, health workers were drained and resources were depleting due to which people were desperately looking for hospital beds, medical oxygen and other necessities. ${ }^{1}$ To prepare for such a crisis, hospitals needed a plan of action to direct their supplies, space, and staff so that optimum care was catered to the patients. ${ }^{2}$ For this purpose, a command centre was set up by the hospital administration department. The history of command centres also known as war rooms dates back to Second World War which was headed by Winston Churchill. It was a room to provide meeting places for the War Cabinet during air raids and also housed a military information centre base. ${ }^{3}$ The country needed a command centre where a designated group of persons think only about COVID-19, design strategies for the upcoming week. COVID-19 war room helps to monitor the available beds, connecting ambulance services and oxygen supply availability. All COVID-19 related information and statistics are collected and managed in one place. The command centre targets for the enhancement of patient outcomes by coordination of care and centralized quality control.

\section{OBJECTIVES}

- Internal communication between the departments concerned with COVID-19 care.

- Appropriate resource allocation in the hospital for COVID-19 care.

- Data compilation and dissemination of the real time data from COVID-19 war room to government organizations.

\section{SETTING UP OF A WAR ROOM}

It was set up by hospital administration department of JSS Hospital and is headed by Director of Hospital. It was established in the master health check up in the second floor of the hospital. The model of the war room is based on the war room in CMC, Vellore.

The war room has a large display which shows live bed status from hospitals across the state which gets updated every hour. It also displays pie charts showing number of oxygen beds, ICU beds, and ventilator beds which are updated throughout a day.

\section{INFRASTRUCTURE}

The room is equipped with:

- Computers having internet connectivity

- Multiple multiline telephones

- Whiteboard and markers

- Printer

-Bulletin Board 
- Hand Sanitizers

- Couch bed for night duty PG's

- Other stationary like paper, pen, etc

COVID-19 war room team comprises of Director, Deputy Director, Medical Superintendent, Deputy MS, Administrative Officer, Senior Residents of Hospital Administration department, PGs of Hospital Administration and Public Health.

\section{ROLES AND RESPONSIBILITIES}

The war room is supervised by the senior residents of department of hospital administration and it is managed by the department of health administration. Routine inspections and rounds are done by the Director of the hospital and Deputy Director of the hospital.

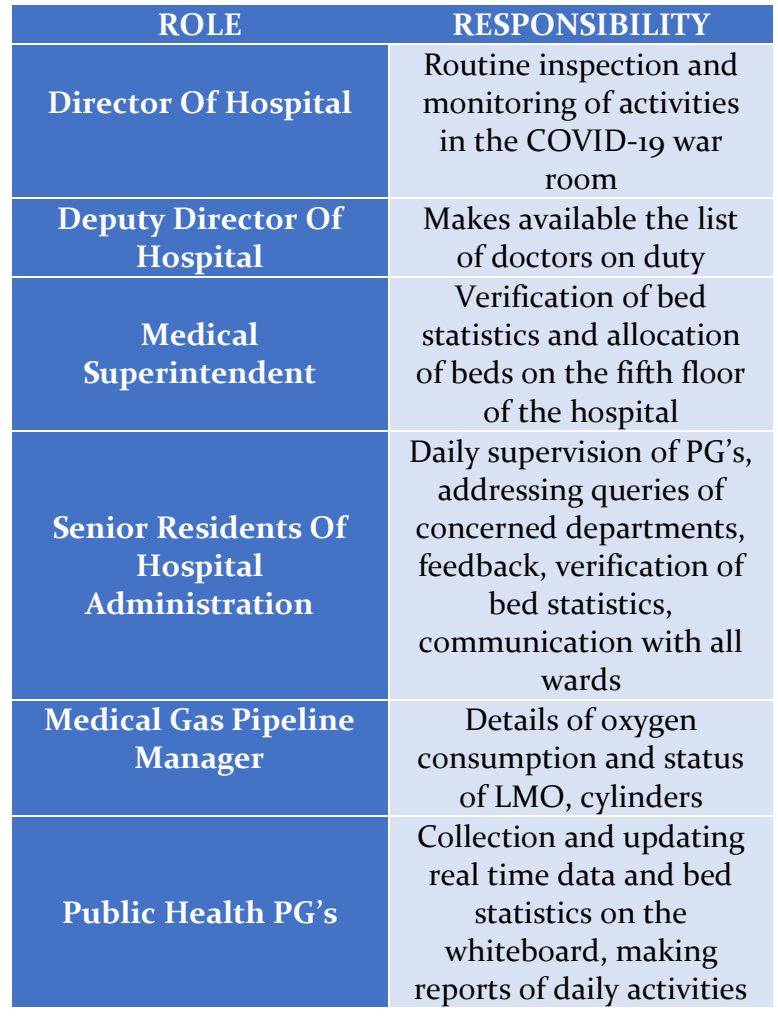

Table 1: Roles and Responsibilities in the War Room

\section{FUNCTIONS}

The COVID-19 war room functions daily in a dedicated manner which helps in strategic planning and managing all the functions efficiently due to the data and information of the hospital being collected in one place. The daily functions of the COVID-19 war room are data management, updating the real time data, managing communication between the wards, addressing queries, resource and stock availability and allocation. The data management includes daily COVID-19 bulletin updates, daily reporting on vaccination, number of tests being done, information on incoming patients, discharge planning, number of positive cases and their status, surveillance and identification of hotspots. It also includes framing of standard operating procedures, imparting training to the field functionaries, and dissemination of accurate information thus streamlining administrative tasks which ensures in smooth functioning in the hospital. Other functions are addressing the grievances of the patients and general public, guiding people regarding the preventive measures to be taken to contain the spread of the COVID-19 virus.

1. Strategic Planning: The main objective of COVID19 command centre is to manage internal communication, resource allocation and management and appropriate data collection and dissemination. To fulfil these objectives, the strategic plan followed is to assign the task of obtaining data from the respective wards dedicated to COVID-19 care, admission and discharge desk, oxygen management team, patient record management team and logistics management. Verification and eventually displaying of the data is planned.

To implement the aforementioned tasks, special training is provided to the members of the nursing staff in assimilation of real time records and updating them in a timely manner to the command centre. The postgraduate students are also trained in data and logistic management and in communication skills.

Furthermore, to evaluate all the functioning, a daily report is prepared and sent to the hospital management. Supervision is done by the Superintendent, Administrative Officer and The Director of the hospital.

2. Data Management: The medical data is structured in spreadsheets and scanned paper documents and then displayed in respective places in hospital portals. The steps involved in data management are as follows:

\section{a. Collection of data}

i. Gathering data about number of normal, oxygenated and ventilated beds occupied and available in different 


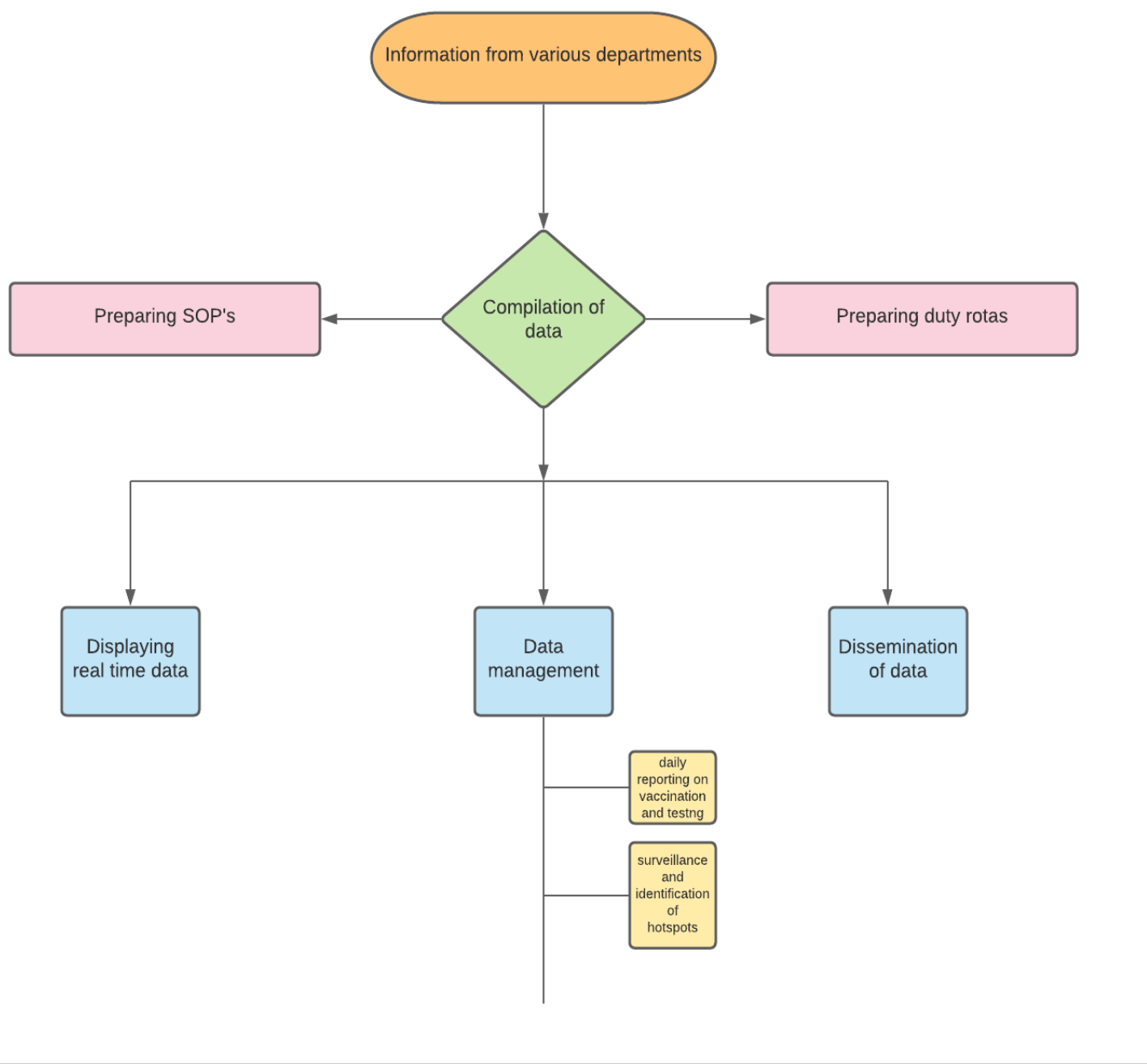

Figure 1. Representation of Compilation and Management of Data in War Room

wards dedicated to COVID-19 care.

ii. Information is gathered about the number of patients reporting in flu clinic, number of people who undergo testing (RTPCR and RAT), number of COVID19 positive patients among those who are tested. iii. The vaccination statistics are assembled from vaccination site.

\section{b. Verification of data collected}

i. The data collected through various sources is double checked and verified with medical records department and nursing in charge of the respective departments. ii. If any discrepancy is noted, changes arere made accordingly.

\section{c. Dissemination of data}

i. The verified data is displayed on the white board inside the war room and outside the hospital.

ii. This data is also sent to government authorities to display on their online portal.

3. Preparation of SOPs and Duty Rotas: Standard Operating Procedures are formulated to record COVID-19 positives, COVID-19 admissions and deaths due to COVID-19. Organising duty rotas for interns, PGs, and staff in the COVID-19 care areas are formed. Figure 1. depicts the representation of compilation and management of data in war room. 


\section{CHALLENGES}

The command centre though works dedicatedly, certain challenges are faced while carrying out the functions. Some of the challenges that list out are miscommunication among concerned departments, data mismatch while compiling data, keeping stocks of COVID-19 care consumables available for use, making beds available on time and displaying real time data. The communication between concerned departments needs to improve, to make the data flow efficient and smooth, which will help in displaying accurate real time data. Cooperation between the concerned departments is crucial to avoid mismatching of data. If the data that is available is accurate, then it will be easier to allocate beds and it will be convenient to keep a check on the stocks of COVID-19 care consumables otherwise shortage might occur. Appropriate communication and continuous updating of data will help to overcome many of challenges.

\section{REFERENCES}

1. Editorial. India's COVID-19-19 emergency. The Lancet. $\quad 2021 ; \quad 397(10286)$ : 1683. https://doi.org/10.1016/So140-6736(21)o1052-7

2. Wong J, Goh QY, Tan Z, Lie SA, Chuan Y, Ng TSY, et al. Preparing for a COVID-19-19 pandemic: a review of operating room outbreak response measures in a large tertiary hospital in Singapore. Can J Anesth. 2020; 67:732-45. https://doi.org/10.1007/s12630-020-01620-9 3. A short history of cabinet war rooms [Internet] Available from: www.iwm.org.uk/history/a-shorthistory-of-the-cabinet-war-rooms

4. Hijjeh M, Al Shaikh L, Alinier G, Selwood D, Malmstrom F, Hassan IF. Critical Care Network in the State of Qatar. Qatar Med J. 2019;2019(2):2. https://doi.org/10.5339/qmj.2019.qccc.2.
5. Prussien K, Lovin S, Markowitz AS. United States: Virtual Trials and War Room Design. (Online Article). Available from: https://www.mondaq.com/unitedstates/operationalimpacts-and-strategy/1014912/virtual-trials-and-warroom-design [Last Accessed on $15^{\text {th }}$ April, 2021]

6. Series 1: COVID-19 War Room - Scaling up BBMP model. (Online Article). Available from: https://smartnet.niua.org/content/1cgdd $36 b$-e182-4ced815b-2af63967393c [Last Accessed on $15^{\text {th }}$ April, 2021] 7. Government of Karnataka. COVID-19 War Room. (Online Article). Available from: https://www.covidwar.karnataka.gov.in/ [Last Accessed on $15^{\text {th }}$ April, 2021]

8. WHO. COVID-19-19 Case definition. (Online Article). Available from: https://www.who.int/publications/i/item/WHO-2019nCoV-Surveillance Case Definition-2020.2 [Last Accessed on $15^{\text {th }}$ April, 2021]

9. Economic Times. Karnataka government sets up war room to monitor supply of oxygen, Remdesivir for COVID-19 treatment. (Online Article). Available from: https://economictimes.indiatimes.com//news/india/ka rnataka-govt-sets-up-war-room-to-monitor-supply-ofoxygen-remdesivir-for-COVID-19-

treatment/articleshow $/ 82177187 . \mathrm{cms} ?$ utm source $=$ cont entofinterestEutm medium=textEutm campaign $=c p p$ $\underline{\text { st. }}$ [Last Accessed on $15^{\text {th }}$ April, 2021]

10. Kausar M, Ranjan R, Singh AR, Siddharth V, Sharma DK. Hospital Administration Control Room: An Effective Concept for Managing Hospital Operation Issues: A Study in Tertiary Care Public Sector Hospital. International Journal of Research Foundation of Hospital and Healthcare Administration 2018;6(2):829o. https://doi.org/10.5005/jp-journals-10035-1097

Cite this article as:

Kulkarni SR, Dhar H. Operationalizing Command Centre in COVID-19 Care Services in a Tertiary Care Teaching Hospital. Int Healthc Res J. 2021;5(6)SC1-SC4. https://doi.org/10.26440/IHRJ/0506.09457

AUTHOR AFFILIATIONS: $\left({ }^{*}\right.$ Corresponding Author)

. MPH PG, JSS Medical College, School of Public Health, Department, of Community Medicine, Mysuru

(Note: Both the authors have contributed equally to this work.)

Source of support: Nil, Conflict of interest: None declared

Contact Corresponding Author at: henna.dhar1827[at]gmail[dot]com 